\title{
HISTÓRIA DO USO DO LIVRO DIDÁTICO UNIVERSITÁRIO: O CASO DO INSTITUTO DE QUÍMICA DA UNIVERSIDADE DE SÃO PAULO
}

\author{
The history of the use of textbooks in the University: \\ the case of the Institute of Chemistry of University \\ of Sao Paulo (IQ-USP)
}

\author{
Karina Aparecida de Freitas Dias de Souza ${ }^{1}$ \\ Cecília Hanna Mate ${ }^{2}$ \\ Paulo Alves Porto ${ }^{3}$
}

\begin{abstract}
Resumo: Os livros didáticos, ao promoverem a circulação de ideias, valores e comportamentos desejados em determinados períodos, constituem importante ferramenta no levantamento da história de uma disciplina. Propõe-se investigar, nesse contexto, qual foi e qual é o papel dos livros didáticos na formação profissional em química, e que lugar eles vêm ocupando na dinâmica das salas de aula, tomando como locus de pesquisa uma importante universidade pública brasileira. Considerando-se fundamentos da história oral, foram entrevistados seis professores, cuja formação e atuação docente ocorreram em diferentes períodos da história da instituição. Os depoimentos sobre o papel do livro didático em suas vidas acadêmicas, como alunos e docentes, permitiram observar diferentes tendências - desde o período em que o ensino de química permaneceu centrado na figura do professor até a recente opção pela adoção de um único livro didático como guia para o desenvolvimento de uma disciplina.
\end{abstract}

Palavras-chave: Livros didáticos. Universidade. História da educação química.

\begin{abstract}
Textbooks constitute important research tools for the history of education, since they promote the circulation of the desired ideas, judgments and behaviours in a specific period. In this context, this paper focuses on the textbook's role in general chemistry courses in different periods, assuming as a research locus a major Brazilian public University. Considering the fundamentals of oral history, six lecturers, whose training and professional work developed in different periods of the history of the institution, were interviewed. The reports about the role of the textbook in their academic lives as students and lecturers revealed different tendencies - from the lecturer-centered process of the early years, to the suggestion of using several textbooks, to the recent adoption of a single textbook as a guide to the general chemistry course.
\end{abstract}

Keywords: Textbooks. University. History of chemical education.

\footnotetext{
${ }^{1}$ Doutoranda em Química, Instituto de Química, Universidade de São Paulo (IQ/USP). São Paulo, SP, Brasil. quimikarina@usp.br

${ }^{2}$ Doutora em História da Educação. Docente, Faculdade de Educação, Universidade de São Paulo. São Paulo, SP, Brasil.hannamat@usp.br

${ }^{3}$ Doutor em Comunicação e Semiótica. Docente, IQ/USP. São Paulo, SP, Brasil. palporto@iq.usp.br

${ }^{1}$ Instituto de Química, Universidade de São Paulo

Av. Prof. Lineu Prestes, 748, Bl. 07 Sup., sala 0761

São Paulo, SP

05.508-000

873

Ciência \&̊ Educação, v. 17, n. 4, p. 873-886, 2011
} 


\section{Introdução}

Independente do nível de ensino, não cabem dúvidas acerca do importante papel dos livros didáticos. Essa atuação não se dá apenas no âmbito da construção individual do conhecimento, mas também como importante influenciador curricular, como destaca Campanario (2001): "Para muitos professores, a escolha de um livro didático significa sua escolha curricular mais importante, pois não é raro que esse instrumento exerça um efeito poderoso sobre seus enfoques docentes e sobre as estratégias de aprendizagem dos alunos" (CAMPANARIO, 2001, p. 352, tradução nossa) $)^{4}$.

De fato, os livros promovem visão organizada do conteúdo trabalhado, resumindo o "consenso disciplinar" da área. Utilizando termos empregados por Kuhn (1970), os livros têm essencial importância na construção da ciência normal, pois reforçam a consideração de uma área do conhecimento como ciência, disseminando-a dentro de uma disciplina.

Um problema se instala, porém, quando se atribui ao livro significado de corpo de conhecimento canonizado, inquestionável e irrevogável, criando-se a tendência à crença de que uma afirmação está em um livro por tratar-se de um fato. De acordo com Coracini (1999), essa tendência é extremamente perigosa, pois leva à

[...] naturalização do uso do livro didático pelo professor (e, consequentemente, pelos alunos), que parece nem sequer perceber a limitação de sua própria liberdade: afinal, cede-se ao livro a autoridade de ditar as regras do jogo, de delimitar os conteúdos e as metodologias a serem adotadas, em conformidade, é claro, com a ideologia vigente. (CORACINI, 1999, p. 37)

O trecho citado chama a atenção para aspecto muito importante do livro didático: seu caráter ideológico, naturalmente advindo da combinação das dimensões pedagógica, econômica e política, que acabam por determinar sua "forma final" (OLIVEIRA; GUIMARÃES; BOMÉNY, 1984). Além das influências das editoras, consequência das exigências de mercado e das características dos consumidores, os conteúdos dos livros são também definidos pelo momento político e suas consequências nos currículos:

[...] o currículo [...] é definido e re-definido em cenário conflituoso de interesses e pressões diversos em que se re-definem os conteúdos da ciência escolar e os modos como esta se apresenta aos estudantes. $\mathrm{O}$ livro-mercadoria não poderia ser refratário a essas mudanças, sendo ao mesmo tempo agente e objeto de tais deslocamentos. (AGUIAR, 2006, p. 3)

\footnotetext{
4 "Para muchos profesores, la elección de un libro de texto supone su decisión curricular más importante, por lo que no es raro que este instrumento ejerza un efecto poderoso sobre sus enfoques docentes y sobre las estrategias de aprendizaje de los alumnos" (CAMPANARIO, 2001, p. 352).
} 
História do uso do livro didático universitário: ...

Torna-se quase inevitável assumir a influência, ainda que não exclusiva e, talvez, não predominante, do livro didático na formação dos estudantes que dele fazem ou fizeram uso em algum momento de sua trajetória acadêmica.

Diante do contexto delineado, os livros didáticos são convertidos, em maior ou menor grau, em referenciais diretos para conteúdos abordados, exemplos utilizados, atividades desenvolvidas e problemas propostos. Daí a importância de serem analisadas as propostas editoriais em suas diferentes dimensões. Porém isso não significa desconsiderar que alterações podem ser sofridas pelos livros didáticos na prática escolar, pois os textos são reinterpretados com base nas histórias de vida dos professores, suas concepções curriculares e a cultura escolar na qual se inserem (ABREU; GOMES; LOPES, 2005).

A maioria das produções acadêmicas relativas aos livros didáticos vem, de maneira muito pertinente, preocupando-se com aspectos relativos ao próprio livro e ao seu conteúdo. Seguindo direção igualmente interessante e importante, produções mais recentes têm evidenciado diversificação de temas e fontes de pesquisa, abarcando outros aspectos relativos ao livro didático, como: sua concepção, produção, uso, relações com políticas públicas, indústria cultural, entre outros (FERNANDES, 2004).

Nesse contexto de diversificações e inovações, porém, os livros destinados ao ensino universitário ${ }^{5}$ permanecem marginais, raramente constituindo objeto de pesquisa.

Qual foi e qual é o papel dos livros didáticos durante a formação profissional? Que lugar eles vêm ocupando na dinâmica das salas de aula nas universidades? Quais contribuições a forma de utilização dos livros didáticos pode trazer à história da educação superior? É na busca de orientações para questões como essas, apresentadas especificamente no contexto da formação universitária em química, que se desenvolve a presente pesquisa. Este trabalho tem por objetivo, nesse contexto, posicionar os livros didáticos no desenvolvimento do curso de Química oferecido pelo Instituto de Química da Universidade de São Paulo (IQ-USP), uma das universidades pioneiras no ensino associado à pesquisa nessa disciplina no país.

Ainda que documentos, como planos de ensino e eventuais relatórios de aula, possam atuar como indicadores do uso dos livros didáticos na universidade, a compreensão do papel histórico assumido por eles será tanto maior quanto for a aproximação daqueles que efetivamente deles fizeram uso não apenas como professores, mas também como estudantes. Nessa perspectiva, as fontes orais, possibilitando o contato com diferentes sujeitos, com distintas vivências e percepções de mundo, podem contribuir para se alcançar o objetivo agora proposto. Essa aproximação não se faz, no entanto, livre de questionamentos e cuidados importantes, inerentes a qualquer metodologia empregada.

A história oral, entendida como trabalho de pesquisa que utiliza fontes orais em diferentes áreas de conhecimento, através da realização de entrevistas gravadas com pessoas

\footnotetext{
${ }^{5}$ Apesar da pouca frequência de utilização do termo livro didático para o nível universitário de ensino, os comumente denominados "livros-texto" universitários podem ser enquadrados na referida categoria se considerarmos que "Livros escolares (ou livros didáticos) são todas as obras cuja intenção original é explicitamente voltada para uso pedagógico e esta intenção é manifestada pelo autor ou editor" (LIVRES apud BEZERRA; BITTENCOURT, 2006, p. 3092).
} 
que viveram ou testemunharam acontecimentos, conjunturas, instituições, modos de vida, ou outros aspectos da história contemporânea (ASSOCIAÇÃO BRASILEIRA DE HISTÓRIA ORAL, 2004), assume considerável importância no contexto da pesquisa em história da educação, se considerarmos que

A história oral é uma história construída em torno de pessoas. Ela lança a vida para dentro da própria história e isso alarga seu campo de ação [...], estimula professores e alunos a se tornarem companheiros de trabalho [...], propicia o contato - e, pois, a compreensão - entre classes sociais e entre gerações [...]. Em suma, contribui para formar seres humanos mais completos. (THOMPSON, 1992, p. 44)

Nesse processo, o pesquisador deve estar atento a algumas características inerentes à utilização da memória como fonte de pesquisa, entre as quais se destaca a subjetividade intrínseca ao pesquisador, ao escolher os depoentes e o assunto a ser tratado na entrevista, e ao próprio entrevistado, uma vez que

[...] o depoente, por sua própria natureza, proporciona uma visão pessoal, subjetiva, parcial da realidade; uma seleção dos eventos do passado, consciente ou inconsciente, que obedece a princípios diferentes daqueles que estão na base da seleção operada pelo historiador ao longo da pesquisa. (VANGELISTA, 2006, p. 186)

A subjetividade associada ao depoente remete a outra característica desse tipo de pesquisa: o fato de que o relato da realidade produz a história como ele mesmo produz a realidade. Assim, muitos momentos das entrevistas coletadas na presente pesquisa evidenciam a situação alertada por Cunha (1997), na qual "As pessoas vão contando suas experiências, crenças e expectativas e, ao mesmo tempo, vão anunciando novas possibilidades, intenções e projetos. Às vezes torna-se até difícil separar o vivido do que está por viver".

A confluência entre experiência e narrativa, no entanto, faz parte da expressão de vida de um indivíduo, constituindo, assim, característica pertinente às pesquisas envolvendo narrativas, especialmente quando essas se encontram baseadas em memórias.

\section{A escolha dos entrevistados}

$\mathrm{Na}$ tentativa de buscar orientações para as questões de pesquisa propostas, foram entrevistados, a partir de fundamentos teóricos da história oral, seis docentes do Instituto de Química da Universidade de São Paulo (IQ-USP), contratados (ao menos oficialmente, como será descrito) no período compreendido entre 1939 e 2002. O primeiro critério balizador da escolha dos depoentes estava relacionado à obtenção de depoimentos procedentes de indivíduos que viveram sua formação profissional e lecionaram em diferentes épocas. Assim, conforme será apresentado, existe um intervalo de 52 anos entre a graduação do professor mais “antigo" e do mais "novo". Além disso, na medida do possível, os professores foram selecio- 
História do uso do livro didático universitário: ...

nados em função de sua atuação (pontual ou contínua) como docente em disciplinas de Quimica Geral, ou equivalentes, oferecidas para alunos de graduação em química no IQ-USP. A escolha desse conjunto de disciplinas deveu-se à sua grande importância e caráter formador, enquanto responsável pela discussão de conceitos introdutórios, mas indispensáveis à continuidade dos estudos de graduação em química.

Ainda que se tenha optado pela não-identificação nominal dos entrevistados, segue breve apresentação dos docentes com alguns dados relevantes para situá-los em seu contexto de formação e atuação profissional.

Professor 1: Esteve entre os primeiros químicos, e, também, entre os primeiros doutores, formados pela Faculdade de Filosofia, Ciências e Letras da Universidade de São Paulo. Foi aluno do Professor Heinrich Rheinboldt, fundador e primeiro gestor do Departamento de Química, que o convidou a assumir o cargo de Assistente Adjunto ainda no final da década de 1930. Iniciou, assim, sua atividade docente, que prosseguiu com grande sucesso: alcançou o cargo de professor catedrático na década de 1950, ocupou diversos cargos de chefia, e continuou sua docência na graduação até a aposentadoria na década de 1980.

Professor 2: Graduou-se, doutorou-se e obteve o título de Livre Docente pela USP. Atuou como Professora Assistente desde a década de 1950, e alcançou o cargo de catedrática no início da década seguinte.

Professor 3: Graduado, no final dos anos 1940, também pela Faculdade de Filosofia, Ciências e Letras da Universidade de São Paulo, ingressou como Professor Assistente Doutor na década seguinte. Durante sua graduação, foi aluno dos Professores 1 e 2.

Professor 4: Graduado em química, pela Universidade de São Paulo, no início dos anos 1970, esteve entre os primeiros alunos a concluir o curso nas atuais instalações do IQUSP na Cidade Universitária. Obteve os títulos de Doutor e de Livre Docente pela mesma instituição. Sua atuação docente iniciou-se na década de 1970, quando foi contratado como Professor Assistente no IQ-USP. Durante sua graduação, foi aluno dos Professores 1, 2 e 3.

Professor 5: Bacharel e licenciada em química pela USP nos anos 1960, obteve seu título de Doutor em Química pela mesma instituição na década seguinte. Foi contratada como docente no IQ-USP após trabalhar por dois anos como Auxiliar de Ensino, ainda na década de 1970. Durante sua graduação, foi aluna dos Professores 1, 2 e 3.

Professor 6: Graduado em química pela Universidade Estadual de Campinas (Unicamp) no final da década de 1980, obteve seu título de Doutor em Química em meados do decênio seguinte pela mesma instituição. Após atuar por mais de um ano como pesquisador associado em uma importante universidade dos EUA, e como professor visitante em uma universidade federal da região sul do Brasil, foi contratado como Professor Doutor no IQUSP no início dos anos 2000.

As entrevistas foram marcadas nos horários e locais que melhor convinham aos depoentes, os quais coincidiram, em sua totalidade, com suas salas de trabalho. Aos professores foi solicitado que discorressem sobre o papel do livro didático em sua vida acadêmica como estudante e como docente. Considerando a imensa diversidade de disciplinas cursadas, seus respectivos professores e, consequentemente, de estratégias de ensino, solicitou-se que, sempre que possível, os entrevistados remetessem suas memórias à disciplina de Química Geral ou equivalente. Os depoimentos foram gravados em áudio digital, mediante autorização dos entrevistados, para posterior transcrição e análise. 
Souza, K. A. F. D.; Mate, C. H.; Porto, P. A.

Antes da apresentação dos depoimentos propriamente ditos, é importante destacar que, ainda que se tratem de pontos de vista individuais, construídos a partir de uma trajetória de vida única, Fernandes (2004) afirma que "Valores e experiências comuns a grupos e sociedades estão presentes, por exemplo, nos significados atribuídos aos indivíduos, aos acontecimentos e aos objetos que emergem nas memórias ou que são preservados como suportes de lembranças" (FERNANDES, 2004, p. 535).

Ainda concordando com a autora, cabe destacar, finalmente, que, como em outros trabalhos que utilizam essa metodologia, os depoimentos coletados poderiam ter sido outros, se tivessem acontecido em outros contextos (CHOPPIN, 2004; FERNANDES, 2004).

\section{O uso do livro didático universitário: o caso do IQ-USP}

A possibilidade de interação com diferentes gerações de estudantes e professores evidenciou diferentes estratégias de uso dos livros didáticos nas salas de aula universitárias e, mesmo, diferentes concepções acerca de seu papel nesse contexto. Sendo essas posturas fortemente influenciadas pelo momento de desenvolvimento do curso e, ainda, pela evolução do próprio Departamento de Química - inicialmente, vinculado à Faculdade de Filosofia, Ciências e Letras, e, posteriormente, incorporado, por ocasião da reforma universitária, ao Instituto de Química da USP - assume especial relevância uma breve apresentação das origens desse instituto, a qual será desenvolvida no decorrer do presente trabalho.

O curso de química da USP surgiu em 1935, quando foi criada a Faculdade de Filosofia, Ciências e Letras dessa universidade. Para sua organização e implementação, foi contratado o professor Heinrich Rheinboldt, da Universidade de Bonn, o qual chegou a São Paulo em julho de 1934, sendo auxiliado pelo professor Heinrich Hauptmann, proveniente da École de Chemie (Genebra), a partir de fevereiro de 1935. As atividades de ensino iniciaram-se na Faculdade de Medicina, sendo posteriormente transferidas, especialmente em razão do espaço físico, para um prédio na Alameda Glette, em janeiro de 1939 (SENISE, 2006).

A forte admiração pelos referidos professores e, por que não dizer, o êxtase causado pela oportunidade de convívio com eles, foi vivenciada por três entrevistados e fica evidente em suas falas. Nesse contexto, surgem os primeiros indícios sobre o papel assumido pelo livro didático nos primórdios do IQ, bem como, em alguns casos, as influências da conduta pedagógica assumida pelos primeiros docentes na posterior atuação profissional dos entrevistados.

Professor 1: Nós tínhamos como referência principal as aulas do Professor Rheinboldt, ele era de uma didática fora do comum, ele foi um professor realmente extraordinário. Ele tinha o dom de saber apresentar a matéria de maneira muito acessivel. Ele tinha uma forma bastante pessoal. Ele não seguia livro nenbum. $O$ que nós fazíamos na época era tomarmos os apontamentos das aulas dele. Quando en tive que substitui-lo afinal, com a morte dele, que ocorren em dezembro de 55, en fui dar o curso dele já em 56, en procurei me espelhar nele primeiro [...]. Eu acho que o que en fiz ele devia fazer, aliás muito melhor do que eu, era vendo várias fontes, ter conhecimentos próprios, as próprias pesquisas, e desta forma elaborar uma aula.

878

Ciência \& Educacãa, v. 17, n. 4, p. 873-886, 2011 
História do uso do livro didático universitário: ...

Professor 2: [...] a gente estudava pelos apontamentos, não estudava pelos livros [...]. Esses professores eram uma novidade aqui. A gente gostava de ouvir as aulas deles [...]. Hoje [o livro] é importante. Naquele tempo a gente queria ouvir os professores.

Professor 3: O livro não tinha presença nenbuma, não, não [...]. O curso se resumia no indivíduo tomar nota de tudo que o professor falava. O professor, tudo que falava botava na pedra [i.e., na lousa], então, principalmente o Rheinboldt, eram aulas maravilhosas, etc., completas. Tinha execução de experiência, mas era o individuo que fazia o seu caderno. Tomando nota de tudo que o professor fazia.

Ainda que seja evidente o papel central ocupado pelo professor, enquanto "fonte" do conhecimento apresentado, é importante atentar para a escassa oferta de livros mencionada pelos professores, especialmente no que se refere às traduções para o português.

Professor 1: Havia também uma dificuldade na indicação de livros porque... Praticamente, naquela época, em 1935/36, eu comecei o curso em 35, nós não tínhamos livros em português, e em espanhol ainda eram poucos, e alguns talvez. nem muito recomendáveis. De maneira que havia os livros em inglês, o Prof. Rheinboldt poderia até ter indicado em alemão, mas ninguém ia entender. Depois, em inglês também poucos ainda tinham o conhecimento, era aquele inglês de colégio.

Algumas considerações devem ser feitas neste momento. Em seu texto "Cem Anos de Química no Brasil", Simão Mathias trata dos acontecimentos que, a partir de 1875, impulsionaram o desenvolvimento da ciência química no país. Já em seu primeiro parágrafo, o autor, que pertenceu à primeira turma de químicos formados pela USP, destaca a publicação da primeira edição de Noções de Chimica Geral (1875), de João Martins Teixeira, como um marco, pois se tratou de "obra que, durante vários decênios, foi amplamente usada no país" (MATHIAS, 1975). A essa publicação seguiram-se várias outras, especialmente no Rio de Janeiro. Considerando que, nesse período, o Ensino Superior de química se dava, além de nas escolas de engenharia, também nas escolas de medicina, podem-se citar as Noções elementares de chimica médica, apresentadas em harmonia com as doutrinas chimicas modernas (1872) e as Noções de Chimica Geral (1881) de Manoel de Morais e Valle. Destacaram-se ainda, no período, os Apontamentos de Chimica, publicados, em 1883, por Álvaro Joaquim de Oliveira. Sobre essa última obra, é interessante destacar alguns comentários tecidos pelo próprio Rheinboldt:

É esta a melhor e mais original obra brasileira que conheço, longe de uma simples compilação ou quase cópia de um ou alguns poucos originais estrangeiros [...]. Uma obra de alto nível filosófico, comparável aos livros clássicos da reforma da teoria química de A. Wurtz e Lothar Meyer [...] e que, se escrita em língua mais acessível, teria sido colocada ao lado das obras clássicas da época. (RHEINBOLDT, 1955, p. 56-57) 
O reconhecimento dedicado por Rheinboldt a algumas das obras publicadas por autores brasileiros, somado ao fato de que existem exemplares de todas as obras mencionadas nas bibliotecas da Faculdade de Medicina e/ou do Conjunto das Químicas da USP - com destaque para as Noções de Chimica Geral de Teixeira, para a qual foi encontrada edição de 1931 (três anos antes do início do curso de química da USP) - conduz à questão de se essas obras seriam adequadas ao ensino que então se implantava na USP. No mesmo texto, Rheinboldt sugere que não, devido ao fato de que essas obras se tornavam rapidamente desatualizadas. Ou seja, o livro de Oliveira era notável para o final do século XIX, mas inadequado para os novos tempos vividos por essa ciência. Sobre uma edição de 1898 do tratado de Oliveira, Rheinboldt escreveu:

Continuando o autor, ainda nessa época e com a mesma justificação, partidário convencido [...] da invariabilidade do número de valência dos elementos químicos, duvidamos ter esta nova edição continuado a prestar serviço benéfico num país em que livros desse gênero se vendem lentamente e ficam em circulação e uso por muito tempo. (RHEINBOLDT, 1955, p. 59)

A própria concepção defendida por Rheinboldt para o Ensino Superior de química não estimulava a busca por livros didáticos. Muitas críticas (nacionais e internacionais) dirigidas ao ensino de química no Brasil do final do século XIX e início do século XX estavam diretamente relacionadas às deficiências no ensino experimental, sendo o ensino da química desenvolvido com base em manuais. A esse respeito, Rheinboldt escreveu:

Não é com livros nem com conferências que se aprende química. Ainda que possua enorme conhecimento de fatos e até conheça a fundo a literatura, um indivíduo pode não ser um verdadeiro químico e não passar de um lexicon ambulante. A base do ensino da química é a situação; o aluno precisa ser educado a fim de aprender a pensar por fenômenos... As principais preleções devem, pois, ser preleções experimentais. (RHEINBOLDT apud MATHIAS, 1975, p. 21-22)

Cabe destacar a grande valorização das anotações feitas pelos alunos nas célebres aulas do mestre, e seu papel como principal fonte de estudo, "tradição" passada às gerações seguintes e preservada apesar do maior acesso às produções editoriais. Essa valorização é evidenciada pelas falas dos Professores 4 e 5, ex-alunos dos Professores 1, 2 e 3, que, inclusive, apresentaram suas anotações, já desgastadas pelo tempo, durante as entrevistas. É interessante notar, no entanto, as distintas funções atribuídas por cada um dos sujeitos, enquanto estudantes de graduação, às notas de aula.

Professor 4: Eu pegava aula por aula do professor [Professor 1], copiava a aula inteirinha, aí eu pegava meia dúzia de livros, levava pra casa e compunha a aula inteirinha a máquina, ou a mão [...]. Isso aqui não são as aulas que en assistia, são as aulas que eu montei. Isso aqui está mais rico que a aula que eu 
História do uso do livro didático universitário: ...

tive. Eu anotei tudo [...]. Como os professores tinham a mesma postura que eu, não adotavam um livro, você pegava uma aula do professor [Professor 1], quem montava a aula depois como en fazia, percebia que ele pegava de 20 fontes, que não era um livro.

Professor 5: Eles davam [o conteúdo] muito completo [...]. A aula era muito completa, mas não tinba referência [livros]. O professor fica contente quando o aluno devolve o que ele ensinou e isso a gente fazia muito bem com os cadernos.

Apesar da forte influência da chamada (pelos próprios professores) "escola rheinboldtiana", a crescente oferta de livros, associada ao aumento do número de vagas para ingressantes - com especial destaque para a década de 1970, quando o atual Instituto de Química foi criado como resultado da reforma universitária - começam a modificar as formas de uso dos livros didáticos e, seja como causa ou consequência, as práticas pedagógicas correntes.

Professor 3: Quando a gente veio pra cá [referindo-se ao atual IQ], ai mudou tudo as coisas. Quando nós viemos pra cá começou a prática de livros, começa a consultar livros. Eu acredito que foi por que os livros tinham muito mais acesso, tinha muito mais produção de livro.

Professor 4: [...] o ensino se massificon [referindo-se ao periodo de 1970 a 19787, as pessoas começaram a dar aula distribuindo carga horária, cada um dá um capitulo, o professor deixou de ter uma proposta pedagógica no curso, virou uma coisa mais de sobrevivência, e perdeu muito essa vinculação de eu querer ensinar algo porque eu acredito naquilo.

Professor 5: Na década de 70, 60 já começou a aparecer livro [...]. Livros assim mais didáticos [...] Nos cursos que eu participei a gente não adotava livro, a gente dava uma lista. Eram recomendados livros, mas a gente nem falava, compra tal livro [...]. Daí começou uma coisa que na Glette [referência às instalações posteriores à Faculdade de Medicina] não tinha: fazer relatório. Então tinha relatórios com perguntas, e os alunos tinham que consultar livros pra responder.

De fato, o curso de química permaneceu instalado na Alameda Glette até dezembro de 1965, quando houve a mudança para o conjunto de pavilhões denominado "Conjunto das Químicas", na atual Cidade Universitária. Essa mudança permitiu aumentar o número de vagas de graduação de 25 para 60, além de dar início a um processo de expansão científica. Associado a esse crescimento, no entanto, Senise (2006) reporta um processo de massificação, com sensíveis modificações na proposta pedagógica do curso:

Com a transferência para a cidade universitária houve grande mudança nas condições de vivência não apenas pelo enorme aumento do espaço físico, como também pela modificação dos métodos de ensino. Com efeito, passou-se de uma forma compacta de ocupação do espaço para 
outra com grande folga provocando um certo distanciamento, como também não foi possível manter o sistema de 'laboratório aberto', pois o indispensável aumento de vagas obrigou a programar o ensino prático com experimentos previamente agendados. Foi o começo da massificação do ensino; é como se de uma atividade artesanal se passasse, quase que de repente, para um sistema de larga escala. (SENISE, 2006, p. 67)

A referência, feita pelo Professor 4, à organização dos docentes responsáveis por uma disciplina segundo os capítulos de determinada obra ("cada um dá um capitulo") aponta para a incipiente prática de "adoção" de um livro didático, a qual é recorrente na fala de outros professores, sendo alvo de críticas de alguns e bandeira de outros, como sugerem as falas anteriores e as que seguem. É interessante notar, especialmente na fala do Professor 3, a composição entre passado e presente, na qual o depoente contrapõe o vivenciado como estudante com sua postura atual enquanto docente.

Professor 3: $O$ aluno nunca compron o livro. $O$ aluno foi muito mal educado nesse sentido. Ele se restringia naquilo que o professor dava. Durante muito tempo foi assim [...]. O curso tem que ser baseado em um livro e o aluno tem que comprar o livro [...]. Todo curso dado tem que ter um livro acompanbando e que o professor mande, por sua conta, estude daqui até lá [...] não importa a qualidade, tem que ter um livro, tá entendendo?

Professor 4: [...] lá [referindo-se ao curso de Farmácia] como eles não gostam de assistir aula, en indicava pra leitura mesmo, falava lê que en vou cobrar, e en cobrava. Foram as piores aulas que en dei na minha vida. Porque o tipo de aula que você fala pro aluno: ob! Lê o livro, sem discutir, o professor perdeu o sentido.

Como evidencia a fala acima transcrita, a forma de utilização do livro didático parece estar diretamente relacionada com a percepção que o professor tem de seus próprios estudantes no que se refere às suas preferências, práticas e, sobretudo, suas potencialidades. É importante ressaltar que não só a forma de utilização do livro é influenciada por essas concepções, mas a própria escolha do livro utilizado.

Professor 5: E os livros mesmo de nivel universitário, na década de 70, o mais famoso era o Mahan 6 , mas era um aluno diferente, uma época diferente. Olhando agora o livro do Mahan [...] a gente já falava sobre o Maban e falava olba é um livro árido, é um livro que não quer ser atraente, ele não faz concessão pra ser agradável, é um livro rigoroso, mas, naquela época, o aluno aguentava isso [...] Lá na década de 70 você tinha alunos brilhantes. Quando começou a entrar em 80 o aluno não seguia, se você puxava muito o aluno não ia... Então eles não iam

${ }^{6}$ MAHAN, B. M. Química: um curso universitário. São Paulo: Edusp, 1970. 
História do uso do livro didático universitário: ...

conseguir pegar um livro mais pesado. O livro tinha que se adaptar ao aluno, conforme a capacidade do aluno acompanhar. Então a gente ficava mesmo mais no Maban, no começo. Depois a gente parou de indicar porque começou a ficar difícil. Principalmente porque o aluno começou a gostar de coisa mais agradável de ler.

É nesse contexto que se destaca a fala do Professor 6, o mais jovem dos depoentes, graduado em 1989. No trecho que segue, o entrevistado trata da prática definida para a disciplina de Química Geral, para os cursos noturnos de graduação em química, que passará por uma série de modificações a partir do presente ano - entre elas, a adoção, agora declarada, de um livro didático. Cabe destacar que, quando rememorando seu tempo de graduação, o depoente referiu-se a prática semelhante.

Professor 6: É porque a gente acha que eles estavam ficando perdidos com as várias opções, enquanto que nós professores temos discernimento suficiente, e os alunos mais velhos, de terceiro, quarto ano, já tem um certo discernimento, a condição de olhar qualé o melhor, qual é o mais adequado. Os alunos que estão entrando, os calouros, primeiro já têm o costume de ter um livro adotado. Então eu acho que surgiu pra não ser um choque muito grande pra eles, que chegam e têm aquele monte de opções e eles nem sabem [...]. Quando chega aluno de terceira, quarta chamada, já não são os melhores alunos, já começa o curso um mês atrasado, então têm muita dificuldade.

A escolha do livro, nesse caso, baseou-se em critérios que ultrapassaram a análise de sua proposta didática:

Professor 6: Aíjá é uma controvérsia porque pro aluno você tem que falar, é esse aqui. Mas sempre chama a atenção deles o fato que um bom livro de Química Geral, que existem vários, cada um escolhe aquele que se adapta melhor. Agora vai ser adotado um livro, não é o que eu mais gosto, mas houve consenso, é o Brown ${ }^{7}[. .$.$] . A minha preferência pessoal é o Kotżs mas, na última reunião foi$ ponderado que o Kotz, tem um grave defeito, ele foi editado em dois volumes em português [...]. Você obriga o aluno a comprar dois volumes, então por isso resolveram indicar o Brown, ele tem algumas falhas, mas, é livro de quimica. Se você ensinar direito em cima do livro. Nós vamos fazer uma lista com vários livros e vamos passar pra eles.

A influência do mercado editorial nas características dos livros disponíveis, bem como na escolha e na avaliação dos livros por parte dos docentes, evidentemente determinante na escolha do livro acima referido, apareceu muito clara também em outros depoimentos:

\footnotetext{
${ }^{7}$ BROWN, T. L. et al. Química: a ciência central. 9. ed. São Paulo: Pearson Prentice Hall, 2005.

${ }^{8}$ KOTZ, J. C.; TREICHEL JR., P. M. Química geral e reações químicas. São Paulo: Pioneira Thomson Learning, 2005.
} 
Souza, K. A. F. D.; Mate, C. H.; Porto, P. A.

Professor 4: [Os livros atuais] São tudo livros de consumo, que têm figurinhas bonitinhas, ilustraçoes lindas, aquela linguagem bem feijão com arroz, superficial, bem de informação. Então é isso que emplacou nos últimos anos. A química como informação, uma coisa agradável, bonita, não uma química como ciência.

Professor 5: [...] muitos livros a gente ganbava, então dependia da oportunidade que a gente teve de ganhar o livro.

Professor 3: [Entrevistador: O que leva um livro a ser usado?] Eu diria o preço, o fácil acesso, aquele livro que o professor conbece. Então ele indica. Porque eu uso o Atkins?? Por que ele é um livro de fácil acesso, todo ano tem edição nova, e todo contexto envolvido nisso, então faz, com que o professor utilize... É a comodidade do contexto que faz a escolha de um certo livro.

Finalizando a apresentação dos depoimentos obtidos e antes de tecer algumas considerações finais acerca dos mesmos, a reflexão sobre os diferentes papéis assumidos pelos livros didáticos nas salas de aula universitárias, fortemente influenciados pelos movimentos sofridos não só na educação, mas também na economia, na figura da ampliação do mercado editorial, torna especialmente oportuna a citação de Demartini (1988, p. 47): “[...] muitas vezes o que julgamos ser uma mudança recente de valores, não o é; problemas que acreditamos serem atuais, também não o são, e, mais que isso, problemas que se acredita existirem por determinados motivos [...] em verdade são historicamente explicados".

\section{Considerações finais}

Por meio dos depoimentos de diferentes gerações de professores de química da USP, foi possível observar algumas tendências em sua relação com os livros didáticos universitários ao longo do tempo. Nos anos que se seguiram à fundação da USP e à criação do Departamento de Química, o ensino de química permaneceu centrado na carismática figura do Prof. Rheinboldt. Vários fatores contribuíram para a não adoção de livros didáticos nesses primeiros anos: a excelência das aulas do mestre alemão; a escassez de textos especializados em português, e o obstáculo representado pelo idioma no que tange ao uso de textos em língua estrangeira, reforçados pela concepção e busca do ensino prático predominante no período. Essa situação prevaleceu também entre os primeiros docentes formados na própria USP, cujos alunos prosseguiram a prática de centrar seus estudos em anotações de aulas.

Um momento que parece ter sido marcante em relação ao uso dos livros didáticos foi a reforma universitária, com a reorganização dos antigos departamentos, a criação do Instituto de Química e a expansão do número de vagas nos cursos de graduação. Nessa época, já estavam disponíveis livros didáticos universitários de química em língua portuguesa, e seu uso

${ }^{9}$ ATKINS, P. W.; JONES, L. Princípios de química. Porto Alegre: Bookman, 2006. 
História do uso do livro didático universitário: ...

passou a ser mais fortemente incentivado. De um modo geral, diferentes professores tinham (e têm) diferentes preferências em relação aos livros didáticos. Assim, tornou-se prática comum oferecer aos estudantes de química sugestões a respeito dos diferentes livros disponíveis no mercado - deixando ao próprio aluno a responsabilidade de estudar com aquele que considerasse mais adequado, ou mesmo recorrendo a mais de um livro.

Especialmente a partir da década de 1990, o IQ-USP pôde cada vez mais renovar seu quadro docente com pesquisadores formados em outras instituições brasileiras, graças à expansão da pesquisa em química em outras universidades, e também à institucionalização da pós-graduação no Brasil. Dessa forma, outros modos de pensar o ensino de química, distintos da bem estabelecida escola rheinboldtiana, foram cada vez mais se fortalecendo no IQ-USP. Além disso, outro fator apontado pelos docentes do IQ-USP é a mudança do perfil dos ingressantes na graduação - que trariam menos conhecimentos de química de seus estudos no Ensino Médio, e que teriam menos autonomia para gerenciar seus próprios estudos. Diante desse quadro, conforme depoimento do Professor 6, os docentes responsáveis pelo ensino de Química Geral nos cursos noturnos de graduação em química decidiram, pela primeira vez, indicar um único livro didático para seus alunos a partir de 2009. Essa experiência também representa, em nosso entender, uma importante mudança no uso dos livros didáticos no IQ-USP.

Muitas outras questões poderiam ser investigadas a partir do tema proposto. Analisados os depoimentos apresentados, ainda que considerada a relativa objetividade da ciência química, será possível afirmar que todas as obras destinadas a seu ensino são equivalentes? Quais seriam as consequências da "adoção" de um livro didático para o desenvolvimento de um curso universitário introdutório de química? Ainda que sejam ponderadas as limitações do uso de um livro único e oferecidas listas bibliográficas, qual será a postura dos estudantes frente a essa situação? Essas e outras relevantes questões permanecem ainda à espera de investigação mais profunda.

\section{Referências}

ABREU, R. G.; GOMES, M. M.; LOPES, A. C. Contextualização e tecnologias em livros didáticos de biologia e química. Investigações em Ensino de Ciências, Porto Alegre, v. 10, n. 3, p. 405-417, 2005.

AGUIAR JR., O. G. Professores, reformas curriculares e livros didáticos de ciências: parâmetros para produção e avaliação do livro didático. In: ENCONTRO DE PESQUISA EM ENSINO DE FÍSICA, 10., 2006, Londrina. Anais... Londrina: SBF, 2006. Disponível em: <http://www.sbf1.sbfisica.org.br/eventos/epef/ix/atas/outros/junior.pdf> Acesso em: 3 out. 2007.

ASSOCIAÇÃO BRASILEIRA DE HISTÓRIA ORAL. Estatuto social da Associação Brasileira de História Oral. Boletim Eletrônico ABHO, n. 27, 2004. Disponível em: $<$ www.historiaoral.org.br/arquivo/download?ID_ARQUIVO=27>. Acesso em: $10 \mathrm{dez}$. 2008 . 
Souza, K. A. F. D.; Mate, C. H.; Porto, P. A.

BEZERRA, R.; BITTENCOURT, C. M. F. Higiene e Saúde nos livros didáticos do professor Felisberto de Carvalho (1880-1960). In: CONGRESSO LUSO-BRASILEIRO DE HISTÓRIA DA EDUCAÇÃO, 6., 2006, Uberlândia. Anais... Uberlândia: UFB, 2006. Disponível em: <http://www.faced.ufu.br/colubhe06/anais/arquivos/apresentacao.htm>. Acesso em: 10 out. 2008.

CAMPANARIO, J. M. ¿Qué puede hacer un profesor como tú o un alumno como el tuyo con un libro de texto como éste? Una relación de actividades poco convencionales.

Enseñanza de las Ciencias, Barcelona, n. 19, v. 3, p. 351-364, 2001.

CHOPPIN, A. História dos livros e das edições didáticas: sobre o estado da arte.

Educação e Pesquisa, São Paulo, v. 30, n. 3, p. 549-566, 2004.

CORACINI, M. J. Interpretação, autoria e legitimação do livro didático. São Paulo: Pontes, 1999.

CORRÊA, R. L. T. O livro escolar como fonte de pesquisa em História da Educação. Cadernos CEDES, Campinas, v. 20, n. 52, p. 11-23, 2000.

CUNHA, M. I. Conta-me agora! As narrativas como alternativas pedagógicas na pesquisa e no ensino. Revista da Faculdade de Educação, São Paulo, v. 23, n. 1-2, p. 185-195, 1997. Disponível em: <http://www.scielo.br/scielo.php?script=sci_arttext\&pid=S010225551997000100010\&lng=en\&nrm $=$ iso\&tlng=pt>. Acesso em: 24 nov. 2008.

DEMARTINI, Z. B. F. Histórias de vida na abordagem de problemas educacionais. In: VON SIMSON, O. M. (Org.). Experimentos com histórias de vida: Itália-Brasil. São Paulo: Vértice: Revista dos Tribunais, 1988. p. 44-105.

FERNANDES, A. T. C. Livros didáticos em dimensões materiais e simbólicas. Educação e Pesquisa, São Paulo, v. 30, n. 3, p. 531-545, 2004.

KUHN, Thomas S. A estrutura das revoluções científicas. 2. ed. Chicago: University of Chicago Press, 1970.

MATHIAS, S. Cem anos de Química no Brasil. São Paulo: Universidade de São Paulo, 1975. (Coleção da Revista de História, 63).

OLIVEIRA, J. B. A.; GUIMARÃES, S. D. P.; BOMÉNY, H. M. B. A política do livro didático. São Paulo: Summus, 1984.

RHEINBOLDT, H. A química no Brasil. In: AZEVEDO, F. (Ed.). As ciências no Brasil. São Paulo: Melhoramentos, 1955. v. 2.

SENISE, P. Origem do Instituto de Química: reminiscências e comentários. São Paulo: Instituto de Química da USP, 2006.

THOMPSON, P. A voz do passado: história oral. 3. ed. Rio de Janeiro: Paz e Terra, 1992.

VANGELISTA, C. Da fala à história: notas em torno da legitimidade da fonte oral. In: LOPES, A. H.; VELLOSO, M. P.; PESAVENTO, S. J. (Org.). História e linguagens: texto, imagem, oralidade e representações. Rio de Janeiro: 7Letras, 2006. p. 185-193.

Artigo recebido em 10/09/2010. Aceito em 06/03/2011. 